\title{
Effect of retrograde autologous priming on lactate and hemoglobin levels of adult patients undergoing coronary artery bypass grafting
}

\author{
Mehwish Naseer, Rehana Feroze, Muhammad Adnan Akram, Fakhar-e-Fayaz
}

Author affiliation:

1. Assistant Professor, Department of Cardiac Anesthesia \& Intensive Care, Army Cardiac Center, Combined Military Hospital, Lahore, Pakistan.

2. Assistant Professor, Department of Anesthesiology \& Intensive Care, Combined Military Hospital Lahore Medical \& Dental College, Lahore, Pakistan.

3. Senior Registrar, Department of Cardiac Anesthesia \& Intensive Care Army Cardiac Center, Combined Military Hospital Lahore, Pakistan.

4. Associate Professor, Department of Cardiac Anesthesia \& Intensive Care, Army Cardiac Center, Combined Military

Hospital, Lahore, Pakistan.

Correspondence: Dr. Mehwish Naseer; E-mail: mwish.naseer@gmail.com; Cell: +92 3044246266

\section{Abstract}

Background: Reduced hemoglobin, excessive transfusions and raised lactate levels are important determinants of patient outcome after cardiopulmonary bypass. Many strategies have been studied for optimum management of these parameters. In this study, we evaluated the impact of retrograde autologous priming (RAP) method on hemoglobin and lactate levels in patients undergoing coronary artery bypass grafting (CABG) on cardiopulmonary bypass.

Methodology: This prospective randomized controlled trial was conducted at Army Cardiac Centre, CMH, Lahore, from January 01, 2021 to June 30, 2021. After approval of institutional ethical committee and taking informed consent from patients, 272 patients undergoing CABG were enrolled. Patients with ages less than $18 \mathrm{y}$, LVEF $\leq 20 \%$, emergency operations, repeat operations, valvular or combined procedures, recent myocardial infarction, with preoperative lactate levels of more than $2 \mathrm{mmol} / \mathrm{L}$ and $\mathrm{Hb}$ of less than $9 \mathrm{gm} / \mathrm{dL}$ and other preoperative systemic diseases or infection were excluded. Patients were divided into two groups. Group A received conventional priming of bypass circuit with ringer lactate, and Group B received RAP with patient's own blood. $\mathrm{Hb}$ and lactate levels were measured in arterial blood gases before induction and upon weaning from bypass.

Results: The demographic features of both groups were identical, Group A patients had significantly high levels of lactate (3.76 \pm 0.81 vs. $2.64 \pm 0.47 \mathrm{mmol} / \mathrm{L}, \mathrm{P}<0.01$ ). Hb levels of patients in RAP (RAP) (Group B) were significantly better $(9 \pm 0.31$ vs. $7.9 \pm$ $0.39 \mathrm{gm} / \mathrm{dL}, \mathrm{P}<0.01$ ) than Group $\mathrm{A}$.

Conclusion: Our study concludes that when compared with crystalloid priming, retrograde autologous priming technique is associated with reduced lactate levels and better hemoglobin levels after cardiopulmonary bypass in patients undergoing coronary artery bypass grafting.

Abbreviations: CABG - Coronary artery bypass grafting; CPB - cardiopulmonary bypass; LVEF - Left ventricular ejection fraction; $\mathrm{Hb}$ - Hemoglobin; RAP - Retrograde autologous priming; FFP - Fresh frozen plasma;

Key words: cardiopulmonary bypass; coronary artery bypass grafting; lactate levels, retrograde autologous priming.

Citation: Naseer M, Feroze R, Akram MA, Fakhar-e-Fayaz. Effect of retrograde autologous priming on lactate and hemoglobin levels of adult patients undergoing coronary artery bypass grafting. Anaesth. pain intensive care 2022;26(1):20-24

DOI: 10.35975/apic.v26i1.1761

Received: October 4, 2021, Reviewed: November 14, 2021, Accepted: January 19, 2022

\section{Introduction}

The main aim of cardiopulmonary bypass (CPB) is to maintain perfusion and oxygenation of the vital organs of the body in the absence of heart and lung function to facilitate surgery on the heart and occasionally in other situations. ${ }^{1}$ It generally requires priming of bypass circuit 
with $1500 \mathrm{ml}$ of crystalloid solution which then mixes with the patient's blood leading to hemodilution. The hemodilution has deleterious effects on organ functions and hemostasis and is associated with need of blood transfusion, which in turn has its own side effects. ${ }^{2}$ The effects on hemostasis may lead to the need for fresh frozen plasma (FFP) and platelets transfusion. The negative impacts of homologous blood transfusion on the postoperative outcome, like pneumonia, sepsis, longer hospital stay, nosocomial infections and renal failure, have also been demonstrated in several studies. ${ }^{3}$

Among many methods studied to reduce transfusion requirement like cell salvage, is the retrograde autologous priming (RAP) of the CPB machine. ${ }^{4}$ It has been studied for its impact on reducing the blood transfusion requirements intraoperatively. Previous studies have shown that this method reduces hemodilution and blood transfusions during CPB by increasing the hematocrit intraoperatively. This method uses the patient's own blood during setting up the pump system. ${ }^{4-8}$

Along with the low hemoglobin $(\mathrm{Hb})$, higher lactate levels (more than $2.0 \mathrm{mmol} / \mathrm{L}$ ) have also been known to predispose patients to acute renal failure and poor postoperative outcomes after going through CPB..$^{5-9}$ Many methods and drugs like remifentanil, thiamine have been investigated to reduce lactate levels on CPB. ${ }^{10-}$ 12

As the effects of RAP are mainly studied in terms of intra operative blood transfusion requirements and no sufficient or inconclusive evidence is present regarding its effects on patients' lactate levels, ${ }^{2-7,13-16}$ we aimed to study the effect of RAP on lactate levels of the patient as a primary outcome and the $\mathrm{Hb}$ levels as a secondary outcome. as both of these parameters effect the postoperative outcome of patients undergoing coronary artery bypass grafting (CABG). We hypothesized that RAP is associated with reduced lactate levels and preserved $\mathrm{Hb}$ levels upon weaning from $\mathrm{CPB}$.

\section{Methodology}

This prospective randomized controlled trial was conducted in Army Cardiac Centre, CMH, Lahore, from January 01, 2021 to June 30, 2021. Ethical committee approval was obtained. A total of 272 patients undergoing $\mathrm{CABG}$ were enrolled in the study after taking informed consent. Non-probability purposive sampling technique was used and the patients were divided into two groups using lottery method. One hundred and thirty-six patients were in Group A which received conventional priming of CPB circuit with a combination of ringer lactate $1200 \mathrm{ml}$, mannitol $100 \mathrm{ml}$ and sodium bicarbonate 50 meq; and for Group B CPB circuit was primed with patient's own blood. Exclusion criteria was age $<18$ y, LVEF $\leq 20 \%$, emergency operations, reoperations, valvular surgeries or combined procedures, recent myocardial infarction, patients with preoperative lactate levels of more than $2 \mathrm{mmol} / \mathrm{L}$ and preoperative $\mathrm{Hb}$ less than $9 \mathrm{gm} / \mathrm{dL}$, preoperative liver disease, preoperative dialysis, hematological or oncological systemic disease or systemic infection. All patients were premedicated with morphine and midazolam IV and anesthetized with propofol and cisatracurium.

The only difference to the standard CPB circuit was a RAP bag. Before starting the RAP, mean blood pressure was elevated to approximately $80 \mathrm{mmHg}$ using small doses of intravenous noradrenaline. Then priming fluid in the arterial line of the heart-lung machine was displaced with patient's own blood using arterial pressure, the venous line was drained by slowly rotating the arterial pump. The priming fluid of the CPB circuit was drained into the RAP bag. The RAP bag remained connected with the venous reservoir for crystalloid fluid replacement during $\mathrm{CPB}$. The retrograde priming procedure took 3 to $5 \mathrm{~min}$. Rest of the management after induction and on CPB was same in both groups and was according to standard protocols of our center. Lactate levels and $\mathrm{Hb}$ in arterial blood were recorded before induction and at weaning from CPB.

\section{Statistical analysis}

Data from each patient was recorded on separate predesigned Performa by the researcher herself. Demographics, preoperative characteristics and postoperative outcomes were recorded for both groups. All data collected was analyzed using SPSS version 22. Qualitative data was analyzed in the form of frequencies and percentages while quantitative data was analyzed in the form of mean and standard deviation. Chi square test was used to assess significance of qualitative data and ttest used to assess significance of quantitative data. A P $\leq 0.05$ was considered as statistically significant.

\section{Results}

The mean age in Group A was $52.72 \pm 7.15 \mathrm{y}$ and in Group B was 53.21 $55.53 \mathrm{y}$.

The BMI in Group A was $26.01 \pm 2.71 \mathrm{~kg} / \mathrm{m}^{2}$ and in Group B was $25.42 \pm 2.52 \mathrm{~kg} / \mathrm{m}^{2}$ (healthy BMI range $\left.18.5-25 \mathrm{~kg} / \mathrm{m}^{2}\right)$.

In Group A 18 (13.2\%) were females and 118 (86.8\%) patients were males. In Group B there were 15 (11\%) female and121 (89\%) male patients (Table 1).

Among the patients of Group A, 36 (26.5\%) were of ASA-II and 100 (73.5\%) were ASA-III. In Group B, 33 $(24.3 \%)$ patients were ASA-II and $103(75.7 \%)$ were ASA-III as shown in Table 1. The difference in ASA status of both groups was not significant $(\mathrm{P}=0.67)$. 


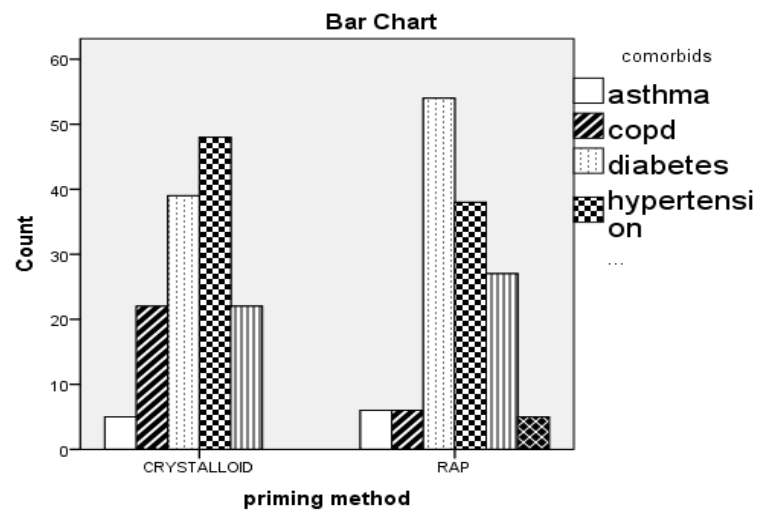

Figure 1: Co-morbids in both groups

The differences in frequency of coronary artery disease (CAD) among the groups was not statistically significant $(\mathrm{p}=0.23)$ (Table 1).

In Group $\mathrm{A}$, the most prevalent comorbid was hypertension (35.3\%), followed by diabetes (28.7\%). In Group B, the most prevalent co morbid was diabetes $(39.7 \%)$, followed by hypertension $(27.9 \%)$, (Table 2 ,

Figure 1). The difference in co-morbids among the both groups was statistically significant $(\mathrm{p}=0.024)$.

The difference in CPB time was statistically not significant among the two groups; being $119.98 \pm 52.47$ vs. $128.11 \pm 47.34 \sec (\mathrm{P}=0.18)$ in Group $\mathrm{A}$ and $\mathrm{B}$ respectively.

The differences between mean $\mathrm{Hb}$ levels and mean lactate values before induction and upon weaning from CPB between the groups were statistically significant (Table 3).

\section{Discussion}

Coronary artery bypass graft surgery is the most commonly performed cardiac operation and as many as $70 \%$ of patients require a blood transfusion despite improvements in cardiac surgical techniques. ${ }^{5}$ Priming of extracorporeal circulation with crystalloids leads to hemodilution and lower intraoperative $\mathrm{Hb}$ levels, while reducing the total $\mathrm{Hb}$ loss during the surgery. ${ }^{3}$

RAP is the other method, in which autologous blood is used to prime the CPB circuit. Hofmann B et al. concluded in their study that patients treated with RAP had significantly Table 1: Demographic data,

\begin{tabular}{|l|l|l|l|}
\hline Demographic features & $\begin{array}{l}\text { Group A } \\
\text { (crystalloid priming) }\end{array}$ & $\begin{array}{l}\text { Group B } \\
\text { (RAP) }\end{array}$ & p \\
\hline Age & $52.72 \pm 7.15$ & $53.21 \pm 5.53$ & 0.52 \\
\hline BMI & $26.01 \pm 2.71$ & $25.42 \pm 2.52$ & 0.06 \\
\hline Gender & $\mathrm{F}=18(13.2 \%)$ & $\mathrm{F}=15(11.0 \%)$ & 0.57 \\
\hline ASA II & $\mathrm{M}=118(86.8 \%)$ & $\mathrm{M}=121(89.0 \%)$ & \\
\hline ASAIII & $36(26.5 \%)$ & $100(73.5 \%)$ & 0.67 \\
\hline Double vessel CAD & $33(24.3 \%)$ & $103(75.7 \%)$ & \\
\hline Triple vessel CAD & $33(24.3 \%)$ & $38(27 \%)$ & 0.23 \\
\hline Single vessel CAD & $82(60.3 \%)$ & $86(63.2 \%)$ & \\
\hline
\end{tabular}

Data presented as mean $\pm S D$, frequency(\%); CAD - Coronary artery disease

Table 2: Comparative co-morbids in both groups (\%)

\begin{tabular}{|c|c|c|c|c|c|c|c|}
\hline Groups & Hypertension & Diabetes & Asthma & COPD & Stroke & None & $P$ value \\
\hline Group A & $35.3 \%$ & $28.7 \%$ & $3.7 \%$ & $16.2 \%$ & 0 & $16.2 \%$ & \multirow[t]{2}{*}{0.024} \\
\hline Group B & $27.9 \%$ & $39.7 \%$ & $4.4 \%$ & $4.4 \%$ & $3.7 \%$ & $19.9 \%$ & \\
\hline
\end{tabular}

\begin{tabular}{|l|l|l|l|}
\hline \multicolumn{3}{|l|}{ Table 3: Comparative blood Hb and lactate levels in two groups } & \\
\hline Study variables & Group A & Group B & p-value \\
\hline Lactate before induction & $1.46 \pm 0.31$ & $1.42 \pm 0.29$ & 0.26 \\
\hline Hb before induction & $11.34 \pm 0.62$ & $11.36 \pm 0.62$ & 0.80 \\
\hline Lactate levels on weaning & $3.76 \pm 0.81$ & $2.64 \pm 0.47$ & 0.000 \\
\hline Hb on weaning & $7.9 \pm 0.39$ & $9.0 \pm 0.31$ & 0.000 \\
\hline
\end{tabular}


It has been observed that RAP treated patients had less intraoperative transfusions but there was no statistically significant difference in lactate levels between the two groups. ${ }^{7-12}$

In our study we observed that RAP technique is not only helpful in maintaining the $\mathrm{Hb}$ levels but also helps to maintain lower lactate levels in patients undergoing $\mathrm{CABG}$ on $\mathrm{CPB}$. Although the difference between the mean $\mathrm{Hb}$ and lactate levels among the two groups was not statistically significant before $\mathrm{CPB}$, there was a significant change in these parameters among both groups upon weaning. The mean $\mathrm{Hb}$ upon weaning from CPB was $7.9 \pm 0.39 \mathrm{gm} / \mathrm{dL}$ in patients with crystalloid priming technique while it was $9.0 \pm 0.31 \mathrm{gm} / \mathrm{dL}$ in patients with RAP $(P=0.000)$. Similarly lactate level in Group A patients was $3.76 \pm 0.81 \mathrm{mmol} / \mathrm{L}$ on weaning as compared to $2.64 \pm 0.47 \mathrm{mmol} / \mathrm{L}$ in Group B patients (P $=0.000$ ). The results prove our hypothesis.

As we know from previous studies that adequate management of these parameters (e.g. blood $\mathrm{Hb}$ and lactate levels) helps to improve patient outcome postoperatively, ${ }^{8,9,12,13}$ implementing RAP technique can be of great help in patient management in cardiac surgery. The cross-clamp time on bypass could be one of the factors that might have effect on the lactate levels of patients and was not included in our present study. It needs to be studied further in future in relation to the priming methods used in present study for its effect on outcome variables.

\section{Conclusion}

We conclude that the patients managed with retrograde autologous priming have better hemoglobin and lactate levels on weaning from cardiopulmonary bypass as compared to conventional priming with crystalloid solutions.

\section{Conflict of interest}

There was no conflict of interest.

\section{Funding sources}

No external funding sources were used.

\section{Authors' contribution}

MN: Concept, study design, manuscript drafting

RF: Statistical analysis

AA: Data collection and interpretation

FF: Critical revision and final approval

\section{References}

1. Cribbon N, Gonoud D, Kevin LG. Cardiopulmonary bypass. Anaesth Intensive Care Med. 2021;22(4):232-237. DOI: 10.1016/j.mpaic.2021.02.006
2. Hofmann B, Kaufmann C, Stiller M, Neitzel T, Wienke A, Silber $\mathrm{RE}$, et al. Positive impact of retrograde autologous priming in adult patients undergoing cardiac surgery: a randomized clinical trial. J Cardiothorac Surg. 2018 May 21;13(1):50. [PubMed] DOI: 10.1186/s13019-018-0739-0

3. Williams HC, Schiller W, Mellert F, Fimmers R, Welz A, Probst $C$. Retrograde autologous priming in surgery of thoracic aortic aneurysm. Interact CardioVasc Thorac Surg. 2019;28:876-83. [PubMed] DOI: 10.1093/icvts/ivz014

4. Reges RV, Vicente WV, Rodrigues AJ, Basseto S, Alves Junior L, Scorzoni Filho A, et al. Retrograde autologous priming in cardiopulmonary bypass in adult patients: effects on blood transfusion and hemodilution. Braz $\mathrm{J}$ Cardiovasc Surg. 2011;26(4):609-16. [PubMed] DOI: 10.5935/16789741.20110052

5. Balachandran S, Cross MH, Karthikeyan S, Mulpur A, Hansbro $\mathrm{SD}$, Hobson P. Retrograde autologous priming of the cardiopulmonary bypass circuit reduces blood transfusion after coronary artery surgery. Annal Thorac Surg. 2002 Jun 1;73(6):1912-8. [PubMed] DOI: 10.1016/s00034975(02)03513-0

6. Fu GW, Nie YF, Jiao ZY, Zhao WZ. Clinical applications of retrograde autologous priming in cardiopulmonary bypass in pediatric cardiac surgery. Braz J Med Biol Res. 2016;49(5):e5138. [PubMed] DOI: 10.1590/1414$431 \times 20165138$

7. Rafiee M, Toutounchi MZ, Yazdani R, Mohammadi N. Effect of retrograde autologous priming on clinical outcome of cardiopulmonary bypassing on patients undergoing coronary artery bypass grafting. Int J Cardiovasc Pract. 2019 Oct:4(4):117-22. DOI: 10.29252/ijcp-26691

8. Mitchell SC, Vinnakota A, Deo SV, Markowitz AH, Sareyyupoglu B, Elgudin $Y$, et al. Relationship between intraoperative serum lactate and hemoglobin levels on postoperative renal function in patients undergoing elective cardiac surgery. J Card Surg. 2018 Jun;33(6):316-321. [PubMed] DOI: 10.1111/jocs.13713

9. Duval B, Besnard T, Mion S, Leuillet S, Jecker O, Labrousse L, et al. Intraoperative changes in blood lactate levels are associated with worse short-term outcomes after cardiac surgery with cardiopulmonary bypass. Perfusion. 2019 Nov;34(8):640-650. [PubMed] DOI: 10.1177/0267659119855857

10. Vranken NP, Babar ZU, Montoya JA, Weerwind PW. Retrograde autologous priming to reduce allogeneic blood transfusion requirements: a systematic review. Perfusion. 2020 Oct;35(7):574-86. [PubMed] DOI: 10.1177/0267659119895474

11. Meng B, Wu K, Wang Y, Zhang S, Zhou X, Ding Y. Effect of retrograde autologous priming based on miniaturized cardiopulmonary bypass in children undergoing open heart surgery: A STROBE compliant retrospective observational study. Medicine (Baltimore). 2020 Jan;99(5):e18801. [PubMed] DOI: 10.1097/MD.0000000000018801

12. Mak NT, Iqbal S, de Varennes B, Khwaja K. Outcomes of postcardiac surgery patients with persistent hyperlactatemia in the intensive care unit: a matched cohort study. J Cardiothorac Surg. 2016 Feb 24;11:33. [PubMed] DOI: 10.1186/s13019016-0411-5 
13. Noguchi S, Saito J, Hashiba E, Kushikata T, Hirota K. Lactate level during cardiopulmonary bypass as a predictor of postoperative outcomes in adult patients undergoing cardiac surgery. JA Clin Rep. 2016;2(1):39. [PubMed] DOI: 10.1186/s40981-016-0064-3

14. Matteucci M, Ferrarese S, Cantore C, Cappabianca G, Massimi G, Mantovani V, et al. Hyperlactatemia during cardiopulmonary bypass: risk factors and impact on surgical results with a focus on the long-term outcome. Perfusion. 2020 Nov;35(8):756-762. [PubMed] DOI: 10.1177/0267659120907440
15. Chaki T, Nawa Y, Tamashiro K, Mizuno E, Hirata N, Yamakage M. Remifentanil prevents increases of blood glucose and lactate levels during cardiopulmonary bypass in pediatric cardiac surgery. Ann Card Anaesth. 2017 Jan-Mar;20(1):33-37. [PubMed] DOI: 10.4103/0971-9784.197827

16. Jahangirifard A, Salajegheh S, Arab S, Mirtajani SB, Radmand $G$, Farzanegan B. Thiamine can decrease Lactate and Creatinine level after Coronary Artery Bypass Surgery in Patients with Mild Systolic Dysfunction. J Cell Mol Anesth. 2019;3(4):136-42. DOI: 10.22037/jcma.v3i4.22603 